\title{
Role of phosphatidic acid during differentiation of Phytophthora palmivora zoospores
}

\author{
Qisen Zhang, $†$ Julia M. Griffith and Bruce R. Grant* \\ Department of Biochemistry, Melbourne University, Parkville, Victoria 3052, Australia
}

(Received 16 July 1991; revised 4 October 1991; accepted 11 November 1991)

\begin{abstract}
Zoospores of the fungus Phytophthora palmivora undergoing synchronous differentiation showed a rapid increase (250\%) in phosphatidic acid (PA) concentration within $20 \mathrm{~s}$ of the inducing stimulus. There were only small $(<\mathbf{1 0 0} \%)$ changes in cGMP and cAMP and inositol phosphates during the same period. There was no consistent change in the concentration of diacyl glycerols during the first five minutes of differentiation. The addition of exogenous PA ( $3 \mu \mathrm{M})$ induced zoospore differentiation, with the optimum concentration dependent upon the $\mathrm{Ca}^{2+}$ concentration in the suspension medium. Other phospholipids were ineffective as inducers. Both PA production and spore differentiation were $\mathrm{Ca}^{2+}$-dependent, and the addition of the $\mathrm{Ca}^{2+}$ channel blocker verapamil, or the removal of exogenous $\mathrm{Ca}^{2+}$ by EGTA addition, both reduced $\mathrm{PA}$ accumulation and slowed differentiation. We suggest that PA production in this organism arises via a stimulus-activated phospholipase $D$, and may act as a second messenger. There is no evidence for any role for cyclic nucleotides or inositol phosphates as second messengers during the early events of zoospore differentiation in this species.
\end{abstract}

\section{Introduction}

Fungi of the family Pythiaceae infect their hosts through motile, wall-less cells termed zoospores (Carlile, 1986). These are attracted to host surfaces by chemotaxis (Cameron \& Carlile, 1978; Goldberg et al., 1989). In order to infect the host, the motile spore must change to a germling, with a transient intermediate, the cyst or cystospore. This transition from zoospore to germling takes less than $30 \mathrm{~min}$ at $25^{\circ} \mathrm{C}$, while encystment is completed in less than $5 \mathrm{~min}$. Encystment and germination are induced by contact with polysaccharides at the host surface (Hinch \& Clarke, 1980; Irving \& Grant, 1984; Longman \& Callow, 1987; Estrada-Garcia et al., 1990). They may also be induced by localized concentrations of $\mathrm{Ca}^{2+}$, which have been shown to occur on root surfaces (Miller \& Gow, 1989).

Axenic suspensions of zoospores of Phytophthora

* Author for correspondence. Tel. (61) 3344 5938; fax (61) 33477730.

$\dagger$ Present address: Crop and Pasture Sciences, University of Western Australia, Nedlands 6009, Australia.

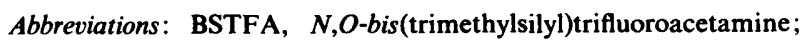
DAG, diacylglycerol; GC/MS, gas chromatography-mass spectrometry; IP, myo-inositol-4-phosphate; $\mathrm{IP}_{3}$, myo-inositol-1,4,5-trisphosphate; $\mathrm{IP}_{4}$, myo-inositol-1,3,4,5-tetrakisphosphate; PA, phosphatidic acid; PLC, phospholipase C; PLD, phospholipase D; RIA, radioimmune assay; TMS, trimethylsilyl. palmivora and Phytophthora cinnamomi undergo this transition in synchrony, in response to a variety of external stimuli, including pectate (Grant et al., 1985), millimolar concentrations of $\mathrm{Ca}^{2+}$ or $\mathrm{Sr}^{2+}$ (Byrt et al., 1982), or vigorous agitation (Tokunaga \& BartnickiGarcia, 1971). Differentiation is dependent upon low concentrations of $\mathrm{Ca}^{2+}$ (Griffith et al., 1988) and is accompanied by increases in the transmembrane fluxes of both this ion (Irving et al., 1984) and $\mathrm{Na}^{+}$(Iser et al., 1989). Zoospore differentiation is also sensitive to external pH (Griffith et al., 1988).

The zoospore is committed to encystment, the first stage of the process, within $20-30 \mathrm{~s}$ of the stimulus, though many of the morphological and metabolic changes are not observed for several minutes (Paktitis $e t$ al., 1986). Although progress has been made in delineating external signals which induce these changes, there is still little information on the means by which the signals are transmitted to the cell interior.

In this paper, we report changes in phosphatidic acid (PA) concentrations during the critical period when zoospores of $P$. palmivora become committed to encystment. There were small increases in cyclic nucleotide levels during this period, but no evidence that either cyclic nucleotides or the inositol phosphate pathway is involved in intracellular signalling during this critical early stage. 


\section{Methods}

Growth conditions. Phytophthora palmivora ATCC 26286 was used throughout the study. The methods for maintenance of the culture and the production and manipulation of zoospores have been described previously (Griffith et al., 1988). Under the conditions used in the experiment, the free $\mathrm{Ca}^{2+}$ in the zoospore suspension was calculated to be approx. $0 \cdot 2 \mu \mathrm{M}$.

Where necessary, spores were labelled with $\left[{ }^{32} \mathrm{P}\right]$ phosphate, (AAEC, Lucas Heights, NSW) or myo- $\left[{ }^{3} \mathrm{H}\right]$ inositol (Amersham Aust.) by growing mycelium on $\mathrm{V}-8$ juice agar to which either $270 \mu \mathrm{Ci}$ $\left.{ }^{32} \mathrm{P}\right]$ phosphate or $10 \mu \mathrm{Ci}$ myo- $\left[2-{ }^{3} \mathrm{H}\right]$ inositol were added per $20 \mathrm{ml}$ of medium, prior to solidification of the agar. Phosphate and inositol concentrations in the medium were shown to be $0.9 \mathrm{mM}$ and $80 \mu \mathrm{M}$, respectively. Phosphate was determined by ion chromatography (Smillie et al., 1988) and myo-inositol as the TMS ether by GC.

Induction of differentiation. All experiments were carried out at $25 \pm 2{ }^{\circ} \mathrm{C}$. Zoospores were normally induced to encyst and germinate by the addition of Tris-pectate (Grant et al., 1985). In some experiments, addition of $3 \mathrm{~mm}-\mathrm{Sr}^{2+}$, or agitation of the spore suspension for $30 \mathrm{~s}$ on a Vortex mixer was used. Suspensions of zoospores contained $2 \times 10^{6}$ cells $\mathrm{ml}^{-1}$. An equal volume of distilled water was added to controls. Where treatments required addition of compounds in ethanol solution, an ethanol control was also included, since ethanol itself induces slow differentiation (Iser et al., 1989). Cells were removed at intervals, and killed by addition of ice-cold perchloric acid or chloroform/methanol as appropriate. Additional samples were taken to observe the stage of differentiation of the population.

Where differentiation was induced by dipalmitoyl PA addition, a chloroform solution of the lipid was taken to dryness in a glass centrifuge tube using a stream of nitrogen. Zoospore suspension medium was added, and the material was brought into suspension by sonication for twenty $1 \mathrm{~min}$ cycles, using an MSE ultrasonicator fitted with an $1 / 8^{\prime \prime}$ probe. The emulsion was cooled in ice for 1 min between each sonication cycle. The same procedure was used where diacylglycerol (DAG) suspensions were prepared.

Cyclic nucleotide analysis. Cyclic nucleotides were determined in $0.5 \mathrm{ml}$ samples of spore suspension $\left(10^{6}\right.$ cells) to which $0.125 \mathrm{ml}$ ice-cold $35 \%(\mathrm{v} / \mathrm{v})$ perchloric acid was added. Extracts were neutralized with $\mathrm{K}_{2} \mathrm{CO}_{3}$, and the perchlorate removed by centrifugation. Supernatants were freeze-dried and the residue taken up in $600 \mu \mathrm{l} 0.05 \mathrm{M}$-acetate buffer, $\mathrm{pH} 5 \cdot 8$, containing $0.01 \%$ thiomersal. cAMP was assayed by the competitive binding assay (Gilman, 1972) and cGMP by RIA assay (Steiner et al., 1972). The first set of measurements used the $\left[{ }^{3} \mathrm{H}\right]-$ labelled nucleotide, and was then confirmed using the more sensitive [ $\left.{ }^{125} \mathrm{I}\right]$-labelled nucleotide. Assay materials were provided as kits (Amersham Aust.). Controls using phosphodiesterase-treated samples were run simultaneously to estimate non-specific binding. The nonspecific binding values have been subtracted from the data reported.

Inositol phosphate analysis. When inositol phosphates were measured by the RIA procedure (Palmer et al., 1989), the extraction procedure was identical to that used for cyclic nucleotides, and a commercial kit (Amersham Aust.) was used for the determinations.

When measurements were made using zoospores labelled with ${ }^{3} \mathrm{H}$ labelled inositol, $15 \mathrm{ml}$ aliquots $\left(1.5 \times 10^{7}\right.$ cells $)$ were used and extracted by the method of Hawkins et al. (1986). The neutralized perchloric acid extract was freeze-dried, and fractionated by anionexchange chromatography (Berridge et al., 1983). The tritium content of the fractions was measured by liquid scintillation and the mass of each inositol phosphate calculated from the specific activity of the inositol in the culture medium. The separation was authenticated by extracting a large sample ( $10^{8}$ spores) and fractionating the aqueous extract by HPLC as described by Irvine et al. (1985). Non-radioactive standards (Sigma) were added to increase the mass of inositol phosphates present. The location of the individual inositides was determined by counting the radioactivity present in the eluant. ATP, measured by absorbance at $254 \mathrm{~nm}$, was used as an internal standard in the separation. Individual radioactive inositol phosphates separated in this manner were then refractionated using the anion-exchange procedure described above.

Lipid analysis. Phosphatidyl inositol phosphates were extracted from ${ }^{32} \mathrm{P}$-labelled zoospores using ice-cold chloroform/methanol (Bligh \& Dyer, 1959), followed by acidified chloroform/methanol (Berridge et al., 1983). Lipids were fractionated on silica gel TLC plates using the method of Jolles et al. (1981) and phosphatidyl inositides were identified by $R_{F}$ values (Rouser et al., 1970). These compounds accounted for $1-3 \%$ of the total lipid phosphorus, with the $\mathrm{PIP}_{2}$ accounting for $<0.01 \%$.

Phosphatidic acid in the total lipid extract was initially identified by its $R_{F}$ value in two dimensional TLC on silica gel plates (Merck) using the solvent systems of Rouser et al. (1970) and by co-chromatography with a dipalmitoyl PA standard (Sigma). Radioactive phospholipids were located by autoradiography using X-Omat RP film (Kodak) exposed for $72 \mathrm{~h}$. After location, radioactive areas were cut from the TLC plate and the radioactivity quantified by liquid scintillation counting. PA was only a minor component of the total lipid phosphorus, always $<1 \%$ of the total, and generally not distinguishable on autoradiographs of unstimulated spore phospholipids.

Analysis of the PA fraction. A single sample containing $2.5 \times 10^{8}$ spores was prepared, stimulated to differentiate, and after $5 \mathrm{~min}$ the total lipids extracted as described above. A separate sample of radioactive zoospore phospholipid sample, containing some 40000 c.p.m. of ${ }^{32} \mathrm{P}$, was added and the mixture was separated using preparative silica gel TLC in two dimensions, with the putative PA located by autoradiography. Material with the $R_{F}$ of PA was extracted in chloroform/methanol $(1: 1)$, dried under nitrogen, transferred to a small vial and saponified and the products neutralized with excess $\mathrm{HCl}$. The $\mathrm{HCl}$ was removed by freeze-drying and the saponified mixture derivatized with BSTFA and separated by GLC as described by Dunstan et al. (1990).

Analysis of lipids by gas chromatography. The diacyl glycerols (DAGs) from whole lipid extracts were analysed as their TMS ethers, using a $12 \mathrm{~m}, 0.33 \mathrm{~mm}$ i.d., aluminium-clad capillary column (S.G.E. HT-08) in a GC fitted with a flame ionization detector. The methods are described in Dunstan et al. (1990). Identification was made by comparing retention times with those of authentic DAGs (dipalmitin, diolein and dicaprin, each a mixture of 1,2 and 1,3 isomers, from Sigma) run as standards, and by demonstrating that the peaks identified as DAGs disappeared following saponification of the lipid sample. Fatty acids were identified by retention times relative to authentic standards (Sigma).

Gas chromatography-mass spectrometry. The products from the saponification of the PA were separated using a Hewlett Packard 5890 gas chromatograph and detected using a Hewlett Packard series 5970 Mass Selective Detector (MS) as described by Dunstan et al. (1990). Limitations on the temperature of the transfer oven prevented the use of identical columns and programmes in GC and GC/MS and thus precluded the direct identification of the DAG isomers by GC/MS.

Statistics and reproducibility. The mean values for cyclic nucleotide and inositol polyphosphate concentrations in stimulated cells were compared with those in controls using Student's $t$ test. In experiments where only single or duplicate samples could be analysed, experiments were repeated at least twice and usually three times. The data presented in each figure or table is representative of the overall results and where there was variation between experiments, this is noted in the text. 


\section{Results}

\section{Changes in cyclic nucleotides}

In unstimulated spores, cAMP concentrations were in the region of 1 pmol per $10^{6}$ cells (Table 1 ), and remained at this level for at least $25 \mathrm{~min}$. Following pectate addition, cAMP concentrations rose to $1.6-2$ pmol per $10^{6}$ cells within $12 \mathrm{~s}$, and at $4 \mathrm{~min}$, reached a maximum of $3.3 \mathrm{pmol}$ per $10^{6}$ cells, before declining to the level of the unstimulated population between 5 and $8 \mathrm{~min}$. Over a series of 10 experiments, the level of cAMP in unstimulated spores varied by as much as $100 \%$, and the magnitude and the timing of the increase shown at $4 \mathrm{~min}$ in Table 1 also varied. However, an increase in cAMP in stimulated spores was always observed during the first two minutes and although small, was significant at the $P<0.05$ level.

Addition of the labdane diterpene forskolin, $(1-50 \mu \mathrm{M})$ had no effect on cAMP concentration in zoospores and did not induce differentiation in either of two trials. The lack of forskolin activity in $P$. palmivora spores suggests either that their adenylate cyclase is insensitive to the drug, in marked contrast to its stimulatory effect on most mammalian adenylate cyclases (Laurenza et al., 1989), or that the drug failed to penetrate the spore. Forskolin could not therefore be used to elevate the cAMP concentrations in the absence of an external stimulus, to determine whether this alone would induce differentiation.

When spore differentiation was induced by the addition of exogenous phosphatidic acid, the concentration of cAMP did not increase over $10 \mathrm{~min}$, and remained constant at 2 pmol per $10^{6}$ cells. In particular, the increase in cAMP at 4 min in pectate-treated cells did not occur. However, the concentration of 2 pmol per $10^{6}$ cells observed in unstimulated cells was within the range observed in pectate-stimulated cells in other experiments (Table 1). As these controls did not undergo rapid differentiation, elevation of cAMP to this level seems insufficient to trigger the synchronous encystment and germination observed in populations treated with pectate or PA.

The concentration of cGMP in unstimulated zoospores was an order of magnitude lower than that of cAMP $\left(0 \cdot 15-0 \cdot 19\right.$ pmol per $10^{6}$ cells, Table 1$)$. Mean cGMP concentration increased only slightly in unstimulated cell populations over more than $30 \mathrm{~min}$. Pectate addition resulted in an increase in cGMP concentration within $12 \mathrm{~s}$ of stimulation, but the increase did not continue. The mean values of the controls drifted upward, and the difference between stimulated and control populations was not significantly different after
Table 1. Cyclic nucleotide levels in P. palmivora zoospores during differentiation

Each data point is the mean of values from four separate experiments. Figures are pmol per $10^{6}$ cells. The values in brackets are the standard deviations. Values with an asterisk were significantly different $(P<0.05)$ from the corresponding control value.

\begin{tabular}{|c|c|c|c|c|}
\hline \multirow[b]{2}{*}{$\begin{array}{l}\text { Time } \\
(\min )\end{array}$} & \multicolumn{2}{|c|}{ cAMP } & \multicolumn{2}{|c|}{ cGMP } \\
\hline & Control & $\begin{array}{l}\text { Pectate } \\
\text { treated }\end{array}$ & Control & $\begin{array}{l}\text { Pectate } \\
\text { treated }\end{array}$ \\
\hline 0.0 & $1 \cdot 0(0 \cdot 3)$ & - & $0.15(0.01)$ & - \\
\hline $0 \cdot 2$ & - & $1.6(0.3)^{*}$ & - & $0.20(0.02)^{*}$ \\
\hline $0 \cdot 3$ & - & - & - & $0.21(0.01)^{*}$ \\
\hline 0.5 & $1 \cdot 1(0 \cdot 3)$ & $1.5(0 \cdot 1)^{*}$ & $0.15(0.02)$ & $0.20(0.01)^{*}$ \\
\hline 0.7 & - & - & - & $0.20(0.03)$ \\
\hline $0 \cdot 8$ & - & - & - & $0.20(0.04)$ \\
\hline $1 \cdot 0$ & $1 \cdot 1(0.2)$ & $1.5(0.2)^{*}$ & $0.16(0.01)$ & $0.23(0.03)^{*}$ \\
\hline 1.5 & - & - & - & $0.20(0.03)$ \\
\hline $2 \cdot 0$ & $1 \cdot 1(0.2)$ & $1.6(0.2)^{*}$ & $0.18(0.03)$ & $0.22(0.02)^{*}$ \\
\hline $4 \cdot 0$ & $1 \cdot 0(0 \cdot 1)$ & $3.3(1.0)^{*}$ & - & $0.20(0.03)$ \\
\hline $5 \cdot 0$ & $1.0(0.4)$ & $1.8(1.3)$ & $0.17(0.04)$ & $0.19(0.01)$ \\
\hline 8.0 & $1.0(0.2)$ & $1.2(0.2)$ & $0.18(0.03)$ & $0.21(0.05)$ \\
\hline $10 \cdot 0$ & $1.0(0.3)$ & $0.9(0.5)$ & $0.18(0.04)$ & $0.21(0.03)$ \\
\hline $15 \cdot 0$ & $1.0(0.4)$ & $0.8(0.6)$ & $0.19(0.04)$ & $0.21(0.05)$ \\
\hline $20 \cdot 0$ & $1 \cdot 1(0 \cdot 1)$ & $0.8(0.2)$ & $0.19(0.02)$ & $0.18(0.03)$ \\
\hline $25 \cdot 0$ & $1.0(0.7)$ & $0.5(0.3)$ & $0.17(0.04)$ & $0.16(0.50)$ \\
\hline $30 \cdot 0$ & $0.6(0.2)$ & $1.0(1.0)$ & $0.17(0.03)$ & $0.19(0.04)$ \\
\hline
\end{tabular}

2 min. cGMP levels were not measured in zoospores stimulated by PA.

\section{Phosphatidyl inositol phosphates and inositol phosphates}

Zoospores contain small amounts of phospholipid with the $R_{F}$ value reported for phosphatidyl inositol-4,5-bisphosphate $\left(\mathrm{PIP}_{2}\right)$. On the assumption that all phosphate pools in the mycelium were of the same specific activity, the absolute maximum concentration ranged between 20 and $50 \mathrm{pmol}$ per $10^{6}$ cells. There was no significant variation in these concentrations or consistent change in their pattern over the $10 \mathrm{~min}$ following pectate addition.

Concentrations of inositol phosphates in stimulated cells were also measured. The $\mathrm{IP}_{3}$ concentrations measured by RIA increased from 4 pmol per $10^{6}$ cells to 9 pmol per $10^{6}$ cells over $8 \mathrm{~min}$ (Fig. 1). Levels in unstimulated cells also increased, and by 8 min equalled those in the stimulated cells $\left(10 \mathrm{pmol}\right.$ per $10^{6}$ cells). These small increases are in contrast to the 6-fold increases observed in mammalian cells, where $\mathrm{IP}_{3}$ signals are known to be important (Palmer et al., 1989). Assuming the zoospore to be a sphere with a mean diameter of $10 \mu \mathrm{m}$, the concentration of $\mathrm{IP}_{3}$ is of the order of $5 \mu \mathrm{M}$, which is higher than in non-stimulated 


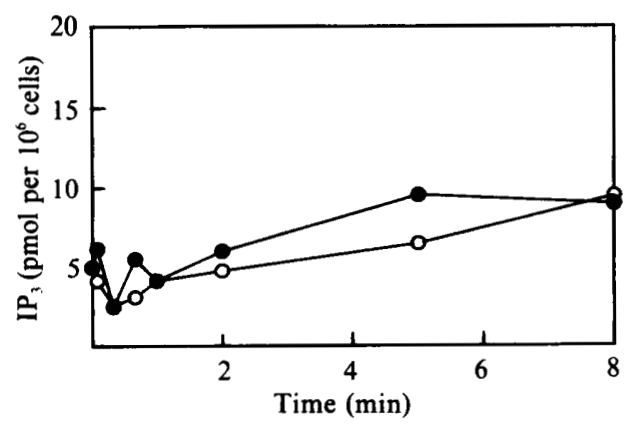

Fig. 1. Inositol-1,4,5-trisphosphate in zoospores during the first $8 \mathrm{~min}$ following pectate addition. The values shown are the means of two separate experiments. Levels in stimulated cells shown as filled circles $(\bullet)$; in unstimulated cells as open circles $(O)$.

animal cells. There were small oscillations in $\mathrm{IP}_{3}$ concentration in stimulated cells during the first minute, and between 2 and $5 \mathrm{~min}$, the $\mathrm{IP}_{3}$ concentrations in the differentiating cells were slightly above those in the controls.

When several inositol phosphates were measured from the radioactivity in each, calculating mass from the specific activity of $m y o-\left[{ }^{3} \mathrm{H}\right]$ inositol in the growth medium, the values for the different inositol phosphates varied widely from one experiment to the next. The IP pool was always the largest, containing as a maximum, one nmol per $10^{6}$ cells. The inositol polyphosphates were present at between 0.5 and $10 \%$ of this level. The IP level increased slowly in stimulated cells, and at $8 \mathrm{~min}$ it was $50 \%$ above that observed prior to stimulation. The increases in $\mathrm{IP}_{2}$ and $\mathrm{IP}_{3}$ concentrations were smaller. The $\mathrm{IP}_{4}$ level showed a $50 \%$ increase at $1 \mathrm{~min}$, but by $90 \mathrm{~s}$ had returned to that in the control and did not change over the remainder of the period.

\section{Diacylglycerols}

At least 9 DAG isomers were distinguished in the total zoospore lipid extract (Fig. 2). While there was an increase in the total level of DAGs over a $5 \mathrm{~min}$ period in stimulated cells, differences between stimulated and control populations were not significant. There were small changes in the relative amounts of the DAG isomers which separated between 27.8 and $28.5 \mathrm{~min}$, but these changes varied from one experiment to the next and no constant pattern was observed.

Addition of phorbol 12-myristate 13-acetate, which mimics the effects of DAGs in cellular metabolism in mammals (Berridge, 1984) did not induce zoospore differentiation at $1-10 \mu \mathrm{M}$. The addition of diolein or dipalmitin $\left(45 \mu \mathrm{g} \mathrm{ml}^{-1}\right)$ was also without effect.

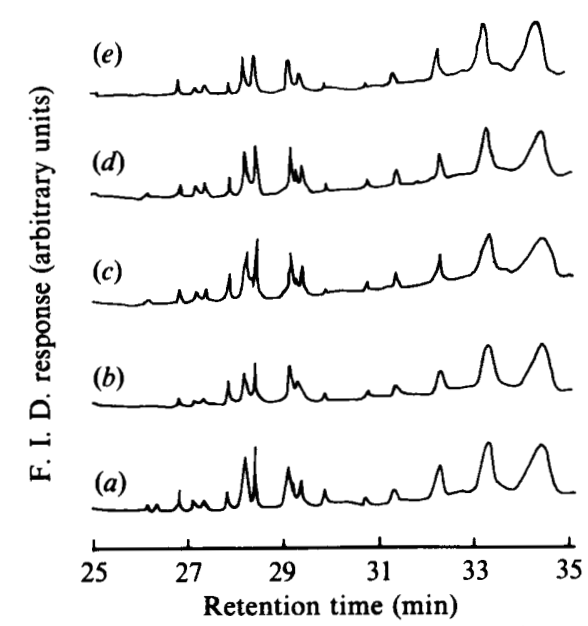

Fig. 2. Diacylglycerols isolated from zoospores following stimulation with Tris-pectate and separated by GC. (a) Extract prepared from spores immediately prior to stimulation; (b) $5 \mathrm{~s}$ post stimulation; (c) $60 \mathrm{~s}$ post stimulation; (d) $5 \mathrm{~min}$ post stimulation; (e) non-stimulated population, $5 \mathrm{~min}$ after time set as zero. Data shown are actual tracings of GC separations, uncorrected for specific response factors of individual DAGs.

\section{Phosphatidic acids}

When ${ }^{32} \mathrm{P}$-labelled phospholipids prepared from stimulated zoospores were separated by two dimensional TLC on silica gel plates, an increase in the amount of radioactivity was observed in a single spot on the chromatogram, located in the region where phosphatidic acids have been shown to run in these solvent systems. The amount of radioactivity in the putative PA increased rapidly in pectate-stimulated zoospores, reaching 1.8 times that of the non-stimulated cells within $10 \mathrm{~s}$ and between 2.5 to 3 times the initial concentration after 2 min (Fig. 3). The PA increase was also observed when cells were induced to differentiate by the addition of $\mathrm{Sr}^{2+}$ or by shaking (Fig. 3). In some experiments, the PA level continued to increase, until by $5 \mathrm{~min}$ it exceeded 4 times the level observed in the cell population prior to stimulus.

The value of the pre-stimulus level of PA was calculated to be $100 \pm 20$ pmol per $10^{6}$ cells based on the specific activity of the $\left.{ }^{[32} \mathrm{P}\right]$ phosphate in the growth medium.

Saponification of the material released palmitic acid and three unsaturated fatty acids; two were $\mathrm{C}: 18$ unsaturated fatty acids and the other a $C: 20$ polyunsaturated fatty acid (Fig. 4), identified by retention times on GC and electron impact ion fragmentation patterns in the GC/MS. The saponification products also included phosphate and glycerol, but no other major peaks were evident. The material on the TLC plates 


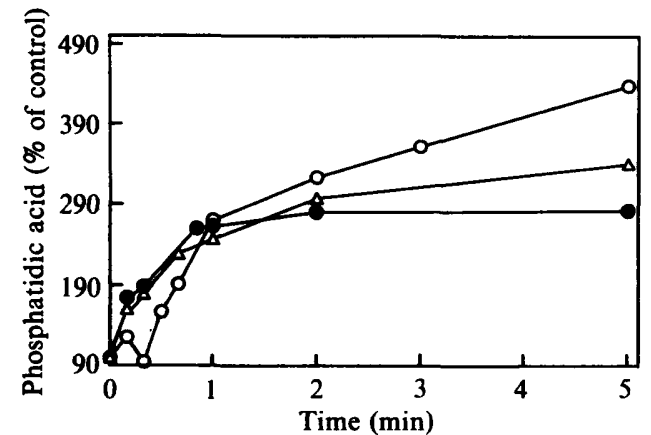

Fig. 3. Changes in phosphatidic acid concentrations in stimulated zoospores. Open circles $(O)$, PA concentrations in cells stimulated with Tris-pectate; filled circles (๑), those stimulated by addition of $3 \mathrm{~mm}$ $\mathrm{Sr}^{2+}$; triangles $(\triangle)$, cells stimulated by shaking. The data shown in this figure are typical of those observed in five different experiments. There was some variation between experiments in the time taken for the PA concentration to reach a plateau. The level of phosphatidic acid in unstimulated cells in this experiment was 115 pmol per $10^{6}$ cells, calculated on the basis of specific activity of the phosphate in the medium on which the mycelia were grown.

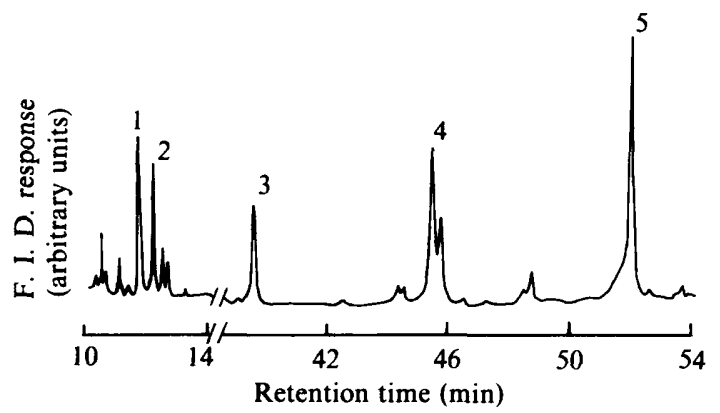

Fig. 4. Profile of total products released from PA following saponification and derivatization. Zoospore lipids were separated by TLC and the material in the PA location eluted and saponified. The material was neutralized and after removal of $\mathrm{HCl}$, was derivatized with BSTFA and separated by GLC. Peak 1 is phosphate; peak 2, glycerol; peak 3, palmitate; peak 4, two unresolved $C: 18$ unsaturated fatty acids; and peak 5, an unsaturated $\mathrm{C}: 20$ fatty acid. The identity of each of the peaks was established by comparing their retention times with authentic standards and was confirmed in a separate GC/MS analysis. Materials eluting before phosphate and immediately following glycerol are from the derivatization reagents. Peaks at 45 and $49 \mathrm{~min}$ were not identified in GC/MS searches, but were not fatty acids.

therefore appears to contain at least two PAs, but nothing else.

When exogenous dipalmitoyl PA was applied to zoospore populations, cells differentiated with an efficiency almost equal to that observed when pectate was added as an inducer, although the onset of both encystment and germination were slightly slower (Fig. 5). Neither phosphatidyl choline, phosphatidyl ethanolamine, phosphatidyl serine nor choline chloride induced

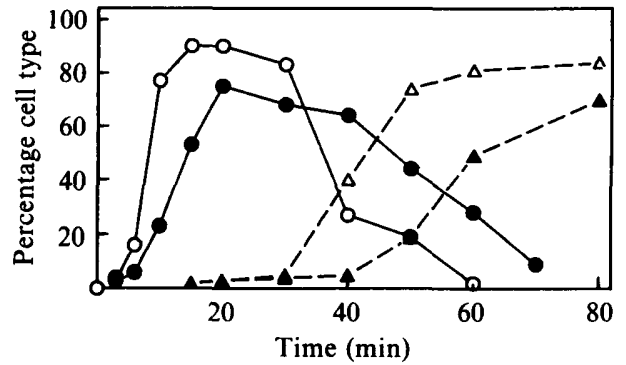

Fig. 5. The kinetics of differentiation of $P$. palmivora zoospores induced by dipalmityl phosphatidic acid compared with that induced by Tris-pectate. The percentage of cysts formed is shown by circles, the percentage of germlings by triangles. Open symbols show populations to which $500 \mu \mathrm{g}$ pectate $\mathrm{ml}^{-1}$ has been added; filled symbols, populations to which $3 \mu \mathrm{M}$-PA had been added.

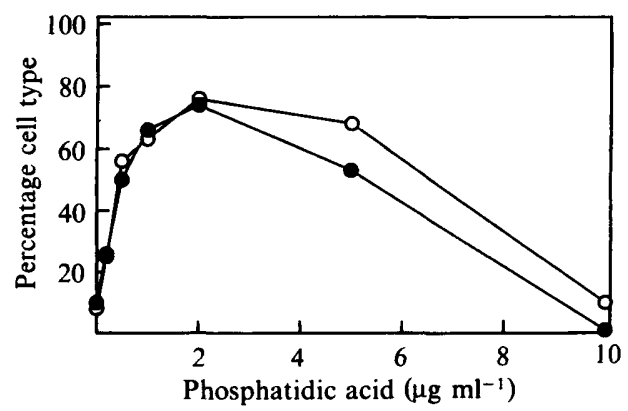

Fig. 6. The effect of the concentration of exogenous dipalmitoyl PA on $P$. palmivora zoospore encystment. Open circles $(O)$, percentage of cysts formed $20 \mathrm{~min}$ after addition of PA; closed circles $(\bullet)$, percentage of germlings present $80 \mathrm{~min}$ after PA addition. The decrease in the percentage of cells completing differentiation at higher PA concentrations is the result of cell lysis.

differentiation. Maximum percentage differentiation was obtained at $2 \mu \mathrm{g} \mathrm{ml}^{-1}(3 \mu \mathrm{M}) \mathrm{PA}$ (Fig. 6). Higher concentrations induced rapid cell lysis, so that percentage of the population forming cysts or germlings fell to almost zero at $10 \mu \mathrm{g} \mathrm{ml}^{-1}$.

\section{Interaction of $\mathrm{PA}$ and $\mathrm{Ca}^{2+}$}

The lytic effect of exogenous PA was dependent on the concentration of $\mathrm{Ca}^{2+}$ in the suspension medium, which was normally $200 \mathrm{nM}$. When free $\mathrm{Ca}^{2+}$ was increased to $400 \mathrm{nM}$, more than $80 \%$ of the zoospore population formed cysts at PA concentrations of $10 \mu \mathrm{g} \mathrm{m}^{-1}$. Conversely, reduction of the free $\mathrm{Ca}^{2+}$ concentrations to $100 \mathrm{nM}$ produced only $20 \%$ encystment at $5 \mu \mathrm{g} \mathrm{ml}^{-1}$.

It had been shown previously that the calcium-channel blocker verapamil reduced the rate at which zoospores underwent differentiation following stimulation (Iser $e t$ 
Table 2. Changes in phosphatidic acid concentration under conditions reducing zoospore differentiation

Tris-pectate, pH 6.2, was supplied at a concentration of $500 \mu \mathrm{g} \mathrm{ml}^{-1}$; verapamil was added to a concentration of $30 \mu \mathrm{M}$.

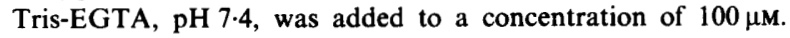
Phosphatidic acid was separated and quantified on the basis of specific activity of phosphate as described in Methods.

\begin{tabular}{lccc}
\hline \multicolumn{1}{c}{ Treatment } & $\begin{array}{c}\text { PA level } \\
(\% \text { control }) \\
\text { at } 20 \mathrm{~s}\end{array}$ & SE (n) & $\begin{array}{r}\% \text { Cysts } \\
\text { at } 10 \text { min }\end{array}$ \\
\hline Control & 100 & - & $<5$ \\
Pectate & 240 & $37(8)$ & 92 \\
Pectate + verapamil & 133 & $8(3)$ & 72 \\
Pectate + Tris-EGTA & 154 & $28(6)$ & 10 \\
\hline \hline
\end{tabular}

SE. standard error

al., 1989). In the presence of verapamil the onset of the production of PA was also significantly reduced (Table 2 ), with only a $33 \%$ increase above the control at $20 \mathrm{~s}$, compared to a $140 \%$ increase in the absence of verapamil. A reduction in spore PA concentration of the same magnitude was observed when Tris/EGTA was used to reduce the external $\mathrm{Ca}^{2+}$ concentration (Table 2). Lowering of external $\mathrm{Ca}^{2+}$ had a much greater effect on encystment (which fell from $92 \%$ to $10 \%$ ) than on PA production, while verapamil reduced PA to a greater degree than it reduced encystment, suggesting that any effect of $\mathrm{Ca}^{2+}$ is not expressed solely through an inhibition of PA production.

\section{Source of phosphatidic acid}

The impermeability of zoospores to most organic compounds (Penington et al., 1989) and their general fragility when subjected to treatments such as electroporation or mild detergent treatment (B. R. Grant and J. R. Iser, unpublished results) made it impossible to introduce either exogenous ATP or phosphate to identify the source of the PA by pulse chase experiments. We were able to introduce some ${ }^{32} \mathbf{P}$ into spores by adding carrier-free $\left[{ }^{32} \mathrm{P}\right]$ phosphate to sporangial suspensions immediately prior to zoospore release. This technique did not give reproducible labelling patterns, but it was sometimes possible to produce zoospores in which nucleotides, including ATP, were heavily labelled, while phospholipids contained little radioactivity. When these zoospores were induced to differentiate, no radiolabelled PA was detected.

In mammalian cells, PA is formed by several pathways. In signalling systems, PA is commonly produced by phosphorylation of DAG, produced by the action of phospholipase C (PLC) on phosphatidyl inositol phosphates (Berridge, 1987). PA appears as the main product, accumulating after a few seconds (Mauco et al., 1984). Transient elevations of diacylglycerols (DAG) are usually observed during the first $10 \mathrm{~s}$ after stimulation and precede the rise in PA (Kroll et al., 1989). No such transient increases in DAGs were observed in this study, nor was there any increase in $\mathrm{IP}_{3}$, the other product of phospholipase $\mathrm{C}$ activity (Berridge, 1984). Studies with mammalian cells are generally carried out at $37^{\circ} \mathrm{C}$, while our experiments were carried out at $25^{\circ} \mathrm{C}$, so transient intermediates should be easier to observe if present. The increases in $\mathrm{IP}_{3}\left(5 \mathrm{pmol}\right.$ per $10^{6}$ cells) were far less than the increases in PA observed (more than $100 \mathrm{pmol}$ per $10^{6}$ cells). The measurements of the increase in all inositide phosphate pools are less reliable, but these could be as high as 500 pmol per $10^{6}$ cells. This change is of the same order as that observed in the PA, and so the possibility that PA arises solely from PLC activity on PIP ${ }_{2}$ cannot be excluded on this basis.

As no incorporation of ${ }^{32} \mathrm{P}$ into the $\mathrm{PA}$ pool was observed where endogenous ATP had been labelled, and only a small amount of label was present in the phospholipid pool, it is unlikely that synthesis of the additional PA occurred de novo from glycerol, through glycerol-3-phosphate and glycerol kinase activity (Brindley, 1985).

A third route to PA production is provided by the action of D-type phospholipases, producing PA directly from phospholipid hydrolysis (Loffelholz, 1989). Phosphatidyl choline (Cabot et al., 1988; Martin, 1988) and phosphatidyl inositol (Cockcroft, 1984) have been reported as preferred substrates for these D-type phospholipases in mammalian cells. As we have detected phospholipase D activity in extracts of these spores, but no phospholipase $\mathrm{C}$ activity, our results are consistent with PA formation through this pathway.

\section{Discussion}

The induction of encystment in $P$. palmivora zoospores is very rapid, and in the presence of pectate is normally followed by germination. The earliest response previously recorded, an increase in the rate of $\mathrm{Ca}^{2+}$ exchange, had a $t_{1 / 2}$ of $30 \mathrm{~s}$ or less (Irving et al., 1984). Although many intracellular messengers may be involved in the regulation of spore germination, any compound involved in the direct transmission of the external signal to encyst must respond within a time scale of seconds, which is also the time scale within which spores become committed to germination (Paktitis et al., 1986).

Substantial increases in the size of the PA pool were observed in all conditions under which zoospore differentiation was induced and took place during this period. 
Analysis of the acyl components of the PA suggested that there was more than one species of PA in the pool, and that palmitate formed one of the acyl groups. Exogenous dipalmitoyl PA induced differentiation very effectively, but it is not clear whether there is a specific acyl group requirement for the induction process. Other phospholipids did not induce spore differentiation, suggesting a specific PA requirement.

The role of PA as a second messenger in the processes of cell differentiation and secretion has recently come under intensive scrutiny in mammalian systems, particularly with the realization that it can arise directly from phospholipase D (PLD) action, as well as indirectly from the phosphorylation of diacylglycerols produced by phospholipase C. Increases in PA levels associated with stimulus-coupled secretion or the resumption of mitotic division have been observed in a wide range of animal cell types. The role of PA and PLD has been reviewed by Exton (1990) and by Shulka \& Halenda (1990). A preliminary report has also appeared, suggesting that PA acts as a second messenger in the signals generated in the pulvini of plants (Coté et al., 1989). So far as we are aware, ours is the first report of an increase in PA in cells of a lower eukaryote under conditions where it might function as a second messenger.

Our results are consistent with PA production by way of a D-type phospholipase, operating independently of phospholipase $\mathrm{C}$ and possibly utilizing phosphatidyl choline as a substrate. The kinetics of PA production suggest that PLD activation may result directly from the external stimulus which induces differentiation. However, it is emphasized that the data do not totally exclude the possibility of a PLC-generated signal coupled with a very rapid kinase reaction.

The role of cyclic nucleotides as second messengers during differentiation in these cells remains unclear. Although both cGMP and cAMP concentrations increased within $20 \mathrm{~s}$ in P. palmivora spores, the increases were relatively small. The larger, transient increase in cAMP at around $4 \mathrm{~min}$ after pectin addition comes too late to be involved in transmission of the external stimulus, but small increases occur over the time that PA begins to increase. It is possible that the magnitude of changes in cyclic nucleotides may be an underestimate, resulting from artificially high levels in the controls, induced by handling stresses. Zoospores do differentiate in the absence of pectin addition, although more slowly and asynchronously. The level of both cyclic nucleotides observed in cells prior to stimulation is at the upper end of the range reported by Goldberg et al. (1973) for a range of unstimulated mammalian cells.

Exogenous cAMP and cGMP both induced $P$. palmivora spore differentiation and the associated $\mathrm{Ca}^{2+}$ efflux (Irving et al., 1984), but only at mM concentrations, as might be expected from the known low permeability of nucleotides. There is no evidence for cyclic nucleotide receptors on the $\boldsymbol{P}$. palmivora spore surface, such as have been demonstrated on the surface of Dictyostelium discoideum (Schaap \& Wang, 1985).

Although cyclic nucleotides have been reported to function as second messengers in spores of the chytrid fungus Blastocladiella emersonii, which differentiate in a similar manner to those of Phytophthora, the evidence is not particularly strong. cAMP-binding proteins have been isolated, and cAMP-dependent protein phosphorylation has been observed in these spores (BrochettoBraga et al., 1982; Gomes et al., 1983), as have elevations in internal cAMP concentrations during germination (Vale et al., 1976; Gomes et al., 1980). However, the kinetics of these increases make it unlikely that CAMP was acting as the second messenger during the initiation of encystment in $B$. emersonii spores any more than in P. palmivora. Moreover, when B. emersonii zoospores were induced to differentiate by the addition of $\mathrm{K}^{+}$, no increase in cAMP level was observed and the addition of permeable $N^{6}-O^{2}$-dibutyryl cyclic nucleotides failed to induce differentiation (Silverman \& Epstein, 1975). We conclude that there is no convincing evidence for cyclic nucleotide involvement in the early stages of differentiation in either species.

Inositol phosphate(s) and diacylglycerols, which are products of phospholipase-C-mediated catabolism of phosphatidyl 4,5-inositol-bisphosphate, are clearly present in $\boldsymbol{P}$. palmivora zoospores. Failure to observe the true increase in $\mathrm{IP}_{3}$ in these experiments could be the result of artificially elevated levels in the unstimulated cells, as for the cyclic nucleotides. However, the small changes in $\mathrm{IP}_{3}$ levels contrast with those observed in PA, and suggest that this pathway has no role in the transmission of the external signals which induce the encystment phase of the differentiation process.

In Phytophthora spores, differentiation is critically dependent upon external $\mathrm{Ca}^{2+}$ concentration, and PA production via PLD requires extracellular $\mathrm{Ca}^{2+}$. The neutral D-type phospholipase from mammalian neutrophils requires $\mathrm{Ca}^{2+}$ concentrations in the $\mathrm{nM}$ to $\mu \mathrm{M}$ range (Balsinde et al., 1989; Huang et al., 1991) which is the same range of $\mathrm{Ca}^{2+}$ concentrations as that required for zoospore differentiation (Griffith et al., 1988). If it is established that a PLD signalling system alone initiates encystment in these spores, they offer a unique opportunity to study this mechanism free from the problems found in animal cells, where both PLC and PLD signal generators are present together.

Part of this work was supported by grants from the ARC to Bruce Grant. We are grateful to Dr R. H. Smillie and Dr R. Dunstan for assistance with the GC/MS analyses, and to Jo Iser for the forskolin 
studies. The suggestion that localized $\mathrm{Ca}^{2+}$ concentrations on roots may be important in spore differentiation came from discussions with B. M. Morris and N. A. R. Gow.

\section{References}

Balsinde, J., Diez, E. \& Mollinedo, F. (1989). Phosphatidylinositolspecific phospholipase $D$, a pathway for generation of a second messenger. European. Journal of Biochemistry 186, 717-724.

BERRIDGE, M. J. (1984). Inositol trisphosphate and diacylglycerol as second messengers. Biochemical Journal 220, 345-360.

BERRIDGE, M. J. (1987). Inositol trisphosphate and diacyglycerol : two interacting second messengers. Annual Review of Biochemistry 56, 159-193.

Berridge, M. J., Dawson, M. C., Downes, C. P., Heslop, J. P. \& IRVING, R. F. (1983). Changes in the levels of inositol phosphates after agonist-dependent hydrolysis of membrane phosphoinositides. Biochemical Journal 212, 473-482.

BLIGH, E. \& DYER, W. (1959). A rapid method of total lipid extraction and purification. Canadian Journal of Biochemistry and Physiology 37, 911-917.

BRINDLEY, D. N. (1985). Metabolism of triacylglycerols. In Biochemistry of Lipids and Membranes, pp. 213-221. Edited by D. E. and J. E. Vance. Menlo Park California: Benjamin Cumings.

Brochetto-Baraga, M., Gomes, S. L. \& da Costa-Maia, J. C. (1982). Studies on the adenosine 3,5 monophosphate-dependent protein kinase of Blastocladiella emersonii. Archives of Biochemistry and Biophysics 217, 295-304.

Byrt, P. N., Irving, H. R. \& Grant, B. R. (1982). The effect of cations on zoospores of the fungus Phytophthora cinnamoni. Journal of General Microbiology 128, 1189-1198.

Савот, M. C., Welsh, C. J., Cao, H.-T. \& Chabbott, H. (1988). The phosphatidylcholine pathway of diacylglycerol formation stimulated by phorbol diesters occurs via phospholipase D activation. FEBS Letters 233, 153-157.

Cameron, J. N. \& Carlile, M. J. (1978). Fatty acids, aldehydes and alcohols as attractants for zoospores of the fungus Phytophthora palmivora. Nature, London 271, 448-449.

Carlile, M. J. (1986). The zoospore and its problems. In Water, Fungi and Plants, pp. 105-118. Edited by P. G. Ayres and L. Boddy. Cambridge: Cambridge University Press.

COCKCrofT, S. (1984). $\mathrm{Ca}^{2+}$-dependent conversion of phosphatidyl inositol to phosphatidate in neutrophils stimulated with fmet-leu-phe or ionophore 23187. Biochimica et Biophysica Acta 795, 37-46.

Cote, G. G., Slatter, R. L. \& Crain, R. C. (1989). Time specific phosphatidic acid synthesis in Samanea saman. Plant Physiology 89, 23.

Dunstan, R. H., Smillie, R. H. \& Grant, B. R. (1990). The effects of sub-toxic levels of phosphonate on the metabolism and potential virulence factors of Phytophthora palmivora. Physiological and Molecular Plant Pathology 36, 205-220.

Estrada-Garcia, T., Ray, T. C., Green, J. R., Callow, J. A. \& KENNEDY, J. F. (1990). Encystment of Pythium aphanidermatum zoospores is induced by root mucilage polysaccharides, pectin and a monoclonal antibody to a surface antigen. Journal of Experimental Botany 41, 693-699.

ExTON, J. H. (1990). Signalling through phosphatidylcholine breakdown. Journal of Biological Chemistry 265, 1-4.

Gilman, A. G. (1972). Protein binding assays for cyclic nucleotides. Advances in Cyclic Nucleotide Research 2, 1-24.

Goldberg, N. D., O'Dea, R. F. \& Kaddox, M. F. (1973). Cyclic AMP. Advances in Cyclic Nucleotide Research 3, 155-223.

Goldberg, N. P., Hawes, M. C. \& Stangellini, M. E. (1989). Specific attraction to and infection of cotton root cap cells by zoospores of Pythium dissotocum. Canadian Journal of Botany 67, 1760-1767.

Gomes, S. L., Mennucci, L. \& da Costa MaIA, J. C. (1980). Induction of Blastocladiella emersonii germination by cAMP $3^{\prime} 5^{\prime}$ monophosphate. Cell Differentiation 9, 169-179.
Gomes, S. L., Juliani, M. H., da Costa Maia, J. C. \& Rangel-Aldao, R. (1983). Autophosphorylation and rapid dephosphorylation of cAMP-dependent protein kinase from Blastocladiella emersonii zoospores. Journal of Biological Chemistry 258, 6972-6978.

GraNT, B. R., IRVING, H. R. \& RADDA, M. (1985). The effect of pectin and related compounds on encystment and germination of Phytophthora palmivora zoospores. Journal of General Microbiology 131, 669-676.

GRIFFITH, J. M., ISER, J. R. \& GRANT, B. R. (1988). Calcium control of differentiation in Phytophthora palmivora. Archives of Microbiology 149, 565-571.

Hawkins, P. T., Stephens, L. \& Downes, C. P. (1986). Rapid formation of inositol 1,3,4,5 tetrakisphosphate and inositol 1,3,4 trisphosphate in rat parotid glands may both result indirectly from receptor-stimulated release of inositol 1,4,5 trisphosphate from phosphatidyl 4,5 bisphosphate. Biochemical Journal 238, 507516.

HiNCH, J. M. \& CLARKE, A. E. (1980). Adhesion of fungal zoospores to root surfaces is mediated by carbohydrate determinants of root slime. Physiological Plant Pathology 16, 303-307.

Hung, R., Kucera, G. L. \& Rittenhouse, S. E. (1991). Elevated cytosolic $\mathrm{Ca}^{2+}$ activates phospholipase $\mathrm{D}$ in human platelets. Journal of Biological Chemistry 266, 1652-1655.

Irvine, R. F., AngaArd, E. F., Letcher, A. J. \& Downé, C. P. (1985). Metabolism of 1,4,5 trisphosphate inositol and 1,3,4 trisphosphate inositol in rat parotid gland. Biochemical Journal 229, 505-511.

IRVING, H. R. \& GRANT, B. R. (1984). The effects of pectin and plant root surface carbohydrates on encystment and development of Phytophthora cinnamomi zoospores. Journal of General Microbiology 130, 1015-1018.

IRviNG, H. R., Griffith, J. M. \& Grant, B. R. (1984). Calcium efflux associated with encystment of Phytophthora palmivora zoospores. Cell Calcium 5, 487-500.

Iser, J. R., Griffith, J. M., Balson, A. \& Grant, B. R. (1989). Accelerated ion fluxes during differentiation of zoospores of Phytophthora palmivora. Cell Differentiation and Development 26, 29-38.

Jolles, J., ZWiers, H., Dekker, A., WiRTZ, K. W. A. \& GisPen, W. H. (1981). Corticotropin-(1-24)-tetracosapeptide affects protein phosphorylation and polyphosphoinositide metabolism in rat brain. Biochemical Journal 194, 283-291.

Kroll, M. H., Zavolw, G. B. \& Schafer, A. J. (1989). Second messenger function of phosphatidic acid in platelet activation. Journal of Cellular Physiology 139, 558-564.

Laurenza, A., SutKowski, E. M. \& Seamon, K. B. (1989). Forskolin : a specific stimulator of adenyl cyclase or a diterpene with multiple sites of action? Trends in Pharmacological Sciences 10, 442-447.

LOFFELHOLZ, K. (1989). Receptor regulation of choline phospholipid hydrolysis. Biochemical Pharmacology 38, 1543-1549.

LONGMAN, D. \& Callow, J. A. (1987). Specific saccharide residues are involved in the recognition of plant root surfaces by zoospores of Pythium aphanidermatum. Physiological Molecular Plant Pathology 30, 139-150.

MARTIN, T. W. (1988). Formation of diacylglycerol by a phospholipase D-phosphatidate phosphatase pathway, specific for phosphatidyl choline in endothelial cells. Biochimica et Biophysica Acta 962, 282-296.

Mauco, G., Dangelmaier, C. A. \& Smith, J. B. (1984). Inositol lipids, phosphatidate and diacylglycerol share stearoylarachidonaylglycerol as a common backbone in thrombin-stimulated human platelets. Biochemical Journal 224, 933-940.

MilleR, A. L. \& Gow, N. A. R. (1989). Correlation between rootgenerated ionic currents, $\mathrm{pH}$, fusiococcin, indole acetic acid and growth of the primary root of Zea mays. Plant Physiology 89, $1198-1206$.

Paktitis, S., Grant, B. R. \& LaWrie, A. C. (1986). Surface changes in Phytophthora palmivora zoospores following induced differentiation. Protoplasma 135, 119-129.

Palmer, S., Hughes, T., Lee, D. Y. \& Wakelam, M. J. O. (1989) Development of a novel Ins $(1,4,5) P_{3}$ specific binding assay. Its use to determine the intracellular concentration of $\operatorname{Ins}(1,4,5) \quad P_{3}$ in 
unstimulated and vasopressin stimulated rat hepatocytes. Cell Signalling 1, 147-156.

Penington, C. J., Iser, J. R., Grant, B. R. \& Gayler, K. R. (1989) Role of RNA and protein synthesis in stimulated germination of zoospores of the pathogenic fungus Phytophthora palmivora. Experimental Mycology 13, 158-168.

Rouser, G., Fleischer, S. \& Yamamoto, A. (1970). Two dimensional thin layer chromatographic separation of polar lipids and determination of phospholipids by phosphorus analysis of spots. Lipids 5 , 494-496.

SCHAAP, P. \& WANG, M. (1985). cAMP induces a transient elevation in cGMP level during early culmination of Dictyostelium minutum. Cell Differentiation 16, 29-33.

Shulka, S. D. \& Halenda, S. P. (1990). Phospholipase D in cell signalling and its relationship to phospholipase C. Life Sciences $\mathbf{4 8 ,}$ 851-866.

Silverman, P. M. \& EPSTEIN, P. M. (1975). Interactions of Blastocladiella emersonii with its environment. In Microbiology 1975, pp. 484-489. Edited by E. Schlessinger. Washington DC: American Society for Microbiology.

Smillie, R. H., Grant, B. R. \& Cribbes, R. L. (1988). Determination of phosphate and phosphite in plant material by gas chromatography-mass spectrometry and ion chromatography. Journal of Chromatography 455, 253-261.

Steiner, A. L., Pagliara, A. S., Chase, L. R. \& Kipnis, D. M. (1972). Radioimmuneassay for cyclic nucleotides 2 . Adenosine 3,5-monophosphate and guanosine 3,5-monophosphate in mammalian tissues and body fluids. Journal of Biological Chemistry 247, 1114-1120.

TokUnaGa, J. \& BarTNICKI-Garcia, S. (1971). Structure and differentiation of the cell wall of Phytophthora palmivora: cysts, hyphae and sporangia. Archiv für Mikrobiologie 79, 293-310.

Vale, V. L., Gomes, S. L., MaiA, J. C. C. \& Mennucci, L. (1976). Transient cyclic AMP accumulation in germinating zoospores of Blastocladiella emersonii. FEBS Letters 67, 189-192. 